\title{
Basal Cell Carcinoma: From the Molecular Understanding of the Pathogenesis to Targeted Therapy of Progressive Disease
}

\author{
Daniela Göppner ${ }^{1}$ and Martin Leverkus ${ }^{2}$ \\ ${ }^{1}$ Department of Dermatology and Venerology, Otto-von-Guericke-University Magdeburg, Leipziger St. 44, 39120 Magdeburg, Germany \\ ${ }^{2}$ Department of Dermatology, Venerology, and Allergology, Medical Faculty Mannheim, Ruprecht-Karls-University of Heidelberg, \\ Theodor-Kutzer-Ufer 1-3, 68167 Mannheim, Germany
}

Correspondence should be addressed to Martin Leverkus, Martin.Leverkus@medma.uni-heidelberg.de

Received 8 July 2010; Accepted 21 September 2010

Academic Editor: Torello Lotti

Copyright (C) 2011 D. Göppner and M. Leverkus. This is an open access article distributed under the Creative Commons Attribution License, which permits unrestricted use, distribution, and reproduction in any medium, provided the original work is properly cited.

\begin{abstract}
Due to intensified research over the past decade, the Hedgehog $(\mathrm{HH})$ pathway has been identified as a pivotal defect implicated in roughly $25 \%$ of all cancers. As one of the most frequent cancer worldwide, the development of Basal cell carcinoma (BCC) due to activation of the $\mathrm{HH}$ pathway has been convincingly demonstrated. Thus the discovery of this central tumor-promoting signalling pathway has not only revolutionized the understanding of BCC carcinogenesis but has also enabled the development of a completely novel therapeutic approach. Targeting just a few of several potential mutations, HH inhibitors such as GDC0449 achieved already the first promising results in metastatic or locally advanced BCC. This paper summarizes the current understanding of BCC carcinogenesis and describes the current "mechanism-based" therapeutic strategies.
\end{abstract}

\section{Introduction}

BCC, the most commonly diagnosed skin cancer in persons of fair complexion, has become the focus of intensified translational debate lately. Following the circumstantial evidence that ewes gave birth to cyclopic and malformed lambs after nibbling on Veratrum californicum, a Corn lily, the causative teratogenic compound, cyclopamine, was discovered $[1,2]$. Increased research on this agenda and the understanding of its functioning led to the discovery of the Hedgehog signalling pathway $(\mathrm{HH})$ as an essential cascade in embryonic development [3]. Proof of a specific mutation in BCC's Hedgehog pathway showed for the first time that an aberrant $\mathrm{HH}$ signalling is also strongly implicated in cancerogenesis of skin tumors [4]. Though a wide range of efficient therapeutic options are well established in the treatment of sporadic BCC, the newly developed $\mathrm{HH}$ inhibitors and first study results give rise to a curative or even secondary-prophylactic approach in hereditary, advanced, or even metastatic variants.

This paper summarizes the current knowledge of clinical aspects and the molecular pathogenesis of this form of skin cancer. Moreover, we discuss current and future therapies that are needed in order to allow efficient treatment of BCC in complicated localization, in patients with multiple tumors or genetic disease predisposing for BCC development, or patients that are not eligible for surgery.

\section{Epidemiology and Clinical Aspects}

First described by Krompecher in 1900 as "carcinoma epitheliale adenoides" [5] and named after its morphological affinity to the normal cell of the basal layer, BCC is the most common keratinocyte skin cancer (KSC) in persons of Caucasian ancestry. Although it presumably develops from epidermal stem cells of the outer root sheat of the hair follikel, the precise origin of BCC is still unknown thus far $[6,7]$. Its incidence is estimated up to 100 cases per 100,000 and even higher depending on geographical or complexion disparities. Hence, BCC as well as other KSCs are often excluded from cancer-registry statistics, thereby underestimating the socioeconomic burden of this form of cancer [8-10]. More common in men than in women, BCC 


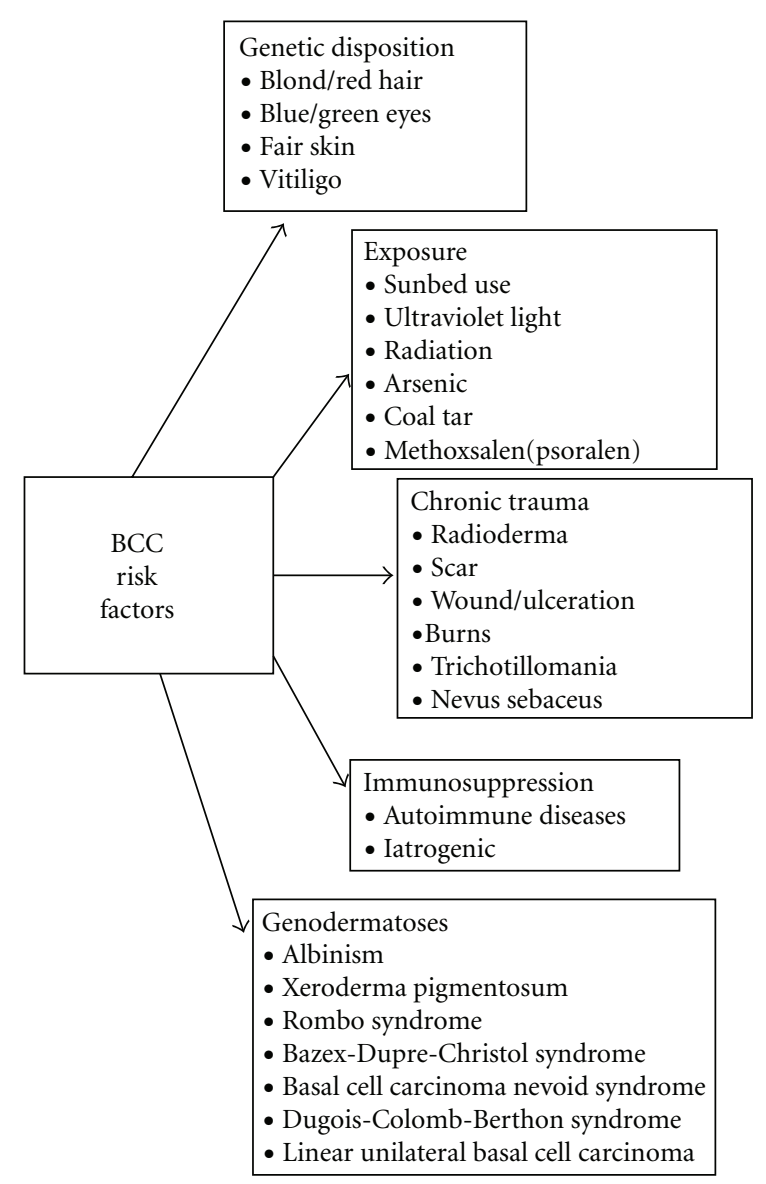

FIGURE 1: Risk factors of BCC, adapted from Rubin et al. [16].

usually arises at an average age of 60 years. Apart from the environmental exposure to arsenic, ionizing radiation, oral methoxsalen (psoralen), and immunosuppressive therapy such as in organ transplant recipients $[11,12]$, persons with a fair skin type-I complexion (including red or blonde hair, light coloured eyes, freckling) and people with a history of intermittent sun exposure and severe sunburn during childhood are at highest risk [13]. In particular ultraviolet (UV) irradiation in inverse correlation with reduced or impaired skin pigmentation is generally considered to be the major risk factor of basal cell carcinoma $[14,15]$. Depending on timing (childhood, adolescence), pattern (intermittent, continuous), source (natural, artificial), and amount (cumulative sun exposure), its impact on BCC development is, however, far more complex and needs further detailed study [16]. Though the rates are still highest for the naturally sun exposed skin of elderly man, the trend over the past decade is clearly towards an increasing incidence of BCC in younger women due to excessive tanning and sunbed use (Figure 1) [17].

The majority of sporadically occurring BCCs arise in sun-exposed areas with over $80 \%$ of all cases developing on the head and neck. Unlike squamous cell carcinoma (SCC), BCCs do not have detectable precursor lesions and usually present themselves de novo as a palpable, localised, translucent tumour with overlying teleangiectasias. For hitherto unknown reasons, they differ in three main clinical as well as histological phenotypes: the nodular BCC exhibiting a pearly rolled border at times with central crusting and ulceration, the superficial subtype with its scaly erythematous patch or plaque-like appearance and the sclerosing, infiltrative, or morpheaform variant that clinically presents as a scar-like, centrally atrophic, whitish, indurate tumour with indistinct margins. Frequently, those three histological subtypes are mixed. In addition to aggressive BCCs such as the infiltrative, micronodular, or basosquamous subtypes, uncommon BCC variants include the clear-cell, granular-cell, or adamantinoid variants, and adnexal differentiation. Pigmented tumours, known to carry p53 mutations [18], may mimic several differential diagnoses including melanoma and therefore need to be confirmed by biopsy. Although erosion and ulceration can develop quite early, especially in the nodular variant, sporadic BCC is in general a slow growing, delayed infiltrating, or destructive tumour that, even in view of other risk factors in terms of a large diameter $>2 \mathrm{~cm}$, incomplete incision and perivascular involvement, metastases only occur after years of existence in $0.55 \%$ of all cases [19]. Once metastasised in regional lymph nodes followed by bone, liver, and lung, the prognosis is poor with a mean survival of at most 3.6 years after diagnosis $[19,20]$.

In contrast to the sporadic variant of BCC, a hereditary disorder, also known as Gorlin syndrome or basal cell nevus syndrome (BCNS), exhibits a marked propensity to develop numerous BCCs already during adolescence and occasionally even in childhood. As an autosomal dominant inherited genodermatosis with an estimated incidence of $1: 150000$ in the general population, BCNS is very rare. It is characterized by a range of developmental anomaliesmost notably in the head and neck area that allowed the oral pathologist and dentist Robert Gorlin to describe it first and a predisposition to various other forms of cancers. Apart from skeletal abnormalities such as splayed ribs, Sprengel and pectus deformity, these patients suffer from ectopic calcification, odontogenic keratocysts, facial dismorphism with macrocephaly, palmoplantar pits and tumours in terms of cardiac and ovarian fibroma, meningeoma, medulloblastoma, rhabdomyosarcoma, mesenteric cysts, and other neuroectodermal tumours [21]. Most prominent among these clinical findings is the early and very strong disposition to develop several, occasionally hundreds of BCCs, especially after radiation given for treatment of progressive BCC or medulloblastoma. It was, however, the intensified research on BCNS with proof of its cause, a mutated PTCH1 gene in the majority of cases, that linked cancer to the $\mathrm{HH}$ signalling pathway for the first time in $1996[4,22]$.

\section{Molecular Pathogenesis}

3.1. Hedgehog Signalling Pathway. The hedgehog $(\mathrm{HH})$ family of intercellular signalling proteins play a pivotal role in many fundamental processes of embryogenic development. They are central to differentiation, growth, pattering, 


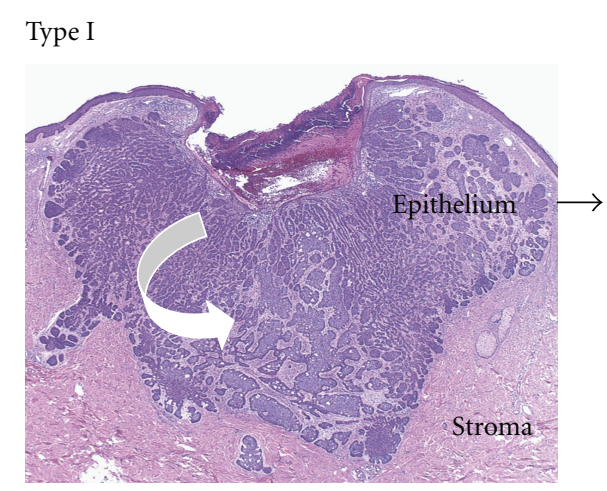

Type II

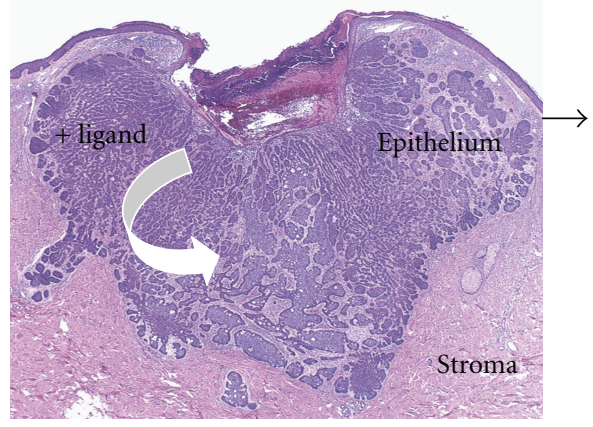

Ligand-independent aberrant $\mathrm{HH}$ activation within the tumor epithelium, for example, BCC

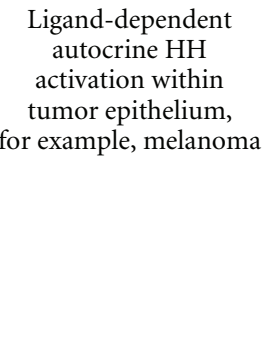

Type III A

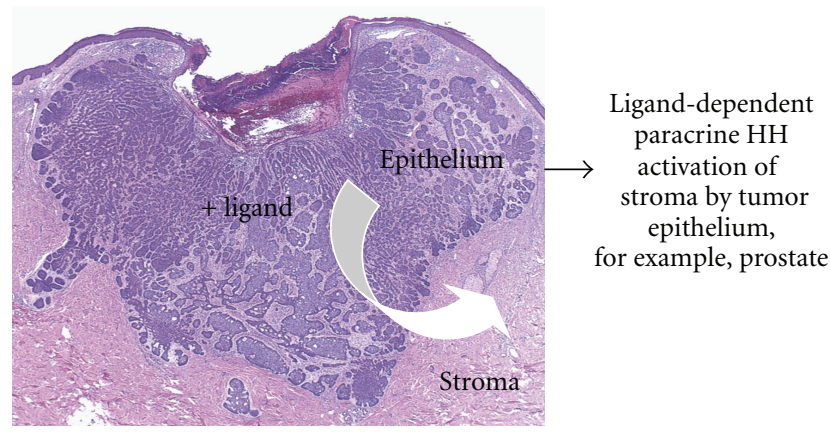

Type III B

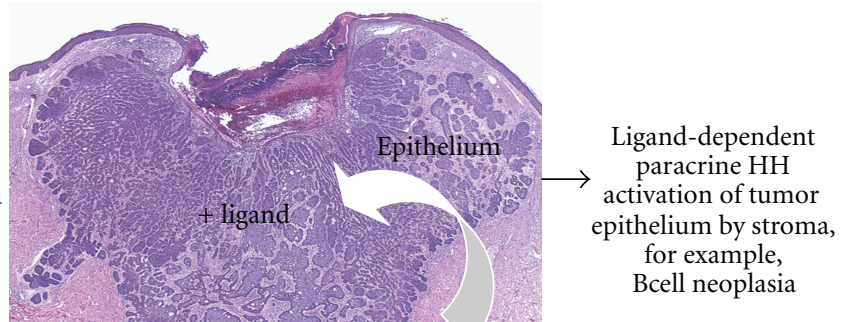

FIGURE 2: HH pathway model systems in cancer, adapted from Scales and de Sauvage [26].

morphogenesis, and function of different cells and organs as well as epithelial and mesenchymal tissue interactions in vertebrates and invertebrates alike [23, 24]. Malfunction or mutation of these proteins lead to substantial impairment as already shown by the prickly, hedgehog-like appearing of mutant flies of Drosophila melanogaster after which the family of proteins was named. Probably by duplication of a single-ancestral gene, mammalians, in contrast to invertebrates with just one $\mathrm{HH}$ gene, develop three different types of homologs: the Sonic, the Desert, and the Indian type. The HH pathway is initiated whenever one of these ligands binds and thereby inactivates the transmembrane tumour-suppressor protein patched homologue 1 ( $\mathrm{PTCH}-$ 1). As a consequence, PTCH-1 then permits its receptor smoothened (SMO), another transmembrane protein, to transmit signals to downstream targets by means of the GLI family of transcription factors. Under normal conditions, and mostly in adults, the hedgehog pathway is ligand dependent and actively repressed because PTCH1 constantly inhibits SMO, the key activator of the GLI pathway. Especially Sonic hedgehog (SHH), as the most widely characterized signalling pathway of the three types, provides a unique example of how the same molecular cascade leads to different pattering in different tissue types solely by distinct transcriptional programs based upon its local concentration [25]. Inappropriate activation due to mutations within this cascade however was clearly identified by a growing body of evidence to be a pivotal cause of carcinogenesis, in particular, in BCNS-associated BCCs and medulloblastoma. According to Scales de Sauvage, so far three different model systems are proposed on how the $\mathrm{HH}$ pathway is involved in the generation of different types of cancer (Figure 2) [26].

3.2. Mutations of Hedgehog Signalling Pathway in BCC. Independent of the underlying oncogenic mutation, in nearly all sporadic as well as BCNS-linked BCCs, uncontrolled stimulations of the hedgehog signalling are found [27, 28]. Due to relatively stable genomes when compared to other extracutaneous cancer, BCCs routinely carry mutations in $30 \%$ to $50 \%$ of the tumors in p53 or PTCH-1 [29-31]. The latter either looses thereby its function (loss of function mutation) or less commonly activates $\mathrm{SMO}$ (gain of function mutation) $[4,22,32]$. Continuously stimulated by SMO, a variety of cell-specific target genes then interfere with the physiological function via endothelial growth factor and angiopoetin (resulting in angiogenesis, cell proliferation, metastasis, and cell survival), ultimately leading to cancer $[26,33]$. SMO itself is mutated only in $10 \%$ of all sporadic BCCs [29]. A few other alternations of the $\mathrm{HH}$ pathway, for example, in SHH or GLI, have been tried to be identified but could not be confirmed so far $[29,34]$.

3.3. Genetic Predispositions, Mutations and Interacting Pathways. In view of the known complex interplay of genes and epigenetic and environmental influences in carcinogenesis, the development of BCC and cancer in general is, however, certainly far more complex and cannot possibly be reduced to three somatic mutations within the hedgehog 
pathway. With the focus on the downstream target genes and effects of $\mathrm{HH}$ signalling, the BCC carcinogenesis probably constitutes an intricate mechanism of several interacting pathways and mutated genes that regulate pigmentation, DNA repair, and apoptosis. Many other mutations have been proven to be implicated in BCC so far. Especially the sequence of downstream mediators in $\mathrm{HH}$ seems to differ in various tissues. Several, such as CD95, BCL-2, $\operatorname{PDGFR} \alpha$, or cFLIP, are currently under investigation [35]. Furthermore, contributions of the FOX gene family, in particular FOXM1 and FOXE1, appear to be involved in downstream signalling [35-38]. As HH target genes, both FOX proteins control for a normal mitosis and are overexpressed in BCC in comparison to normal keratinocytes $[39,40]$. But it is not yet understood which changes are crucial in BCC and therefore represent "drivers" but not "passengers" during tumorigenesis of BCC $[14,41]$.

A similar lack of knowledge still exists for the interaction of the GLI signalling pathway with other cellular signals. The Phosphoinositol-3-kinase (PI3K) cascade interacts with $\mathrm{SHH}$ in at least two ways. While it inhibits protein kinase A (PKA-) mediated phosphorylation, it also stabilizes GLI2. On the other hand, $\mathrm{SHH}$ activates PI3K, for example, in prostate cancer [42]. But up to now, no proof for PI3K involvement in BCC carcinogenesis could be given [14]. The relationship of the Ras/Raf signalling pathway and BCC is less well defined [29]. In comparison, the obvious requirement of Wnt signalling in the downstream activation of $\mathrm{HH}$ for these tumours [43] hints at novel possibilities to the therapeutic approach in BCC in addition to $\mathrm{HH}$ inhibitors (described below) [14].

From a clinical point of view, the most convincing yet rather confusing-due to several contradicting resultsresearch focuses on the association of BCC with pigmentation and DNA repair genes, respectively. At least for sporadic BCCs as the classic UV-induced variant and those that arise in patients with xeroderma pigmentosum (XP), a frequent type of PTCH1 and p53 mutations could be identified [44].

The clinical presumption that the increased incidence of BCC in elderly could be a consequence of diminished DNA repair due to aging seems therefore not so farfetched [45]. Hence, the repair of UV-induced damage should reduce BCC development $[44,46]$, although the use of sunscreens failed to lower the risk of BCC to date [47]. For several DNA repair gene variants such as XRCC1, XRCC3, XPA, and XPD, a significant association with $\mathrm{BCC}$ risk has been reported [48]. The polymorphism of those mutants involved is unfortunately reflected by diverse and often contradictory results [49-52]. A variant once proven to be significant [48] was refuted in another study [53] or was, in part, not BCCspecific at all [54].

Similarly unpersuasive are the results on melanocortin 1 receptor gene (MCIR), the major known genetic variant influencing the degree of skin pigmentation. Although it was clearly shown that the nonfunctional variant of MCIR had a dose-dependent impact on the incidence of BCC and melanoma, the consecutive lack in pigmentation itself did not influence the result $[54,55]$. A different mechanism in terms of a paracrine role or distant modulation of proliferation and differentiation of keratinocytes by MCIR has also been suggested $[56,57]$. In general, the functioning of pigmentation and DNA repair in healthy individuals, let alone in skin cancer, is so far too little, or at best partially, understood in order to pave the way for prevention or let alone treatment of BCC.

\section{Current and Future Treatment Options}

4.1. Current Standard of Care. A wide range of several effective therapeutic options are available for the therapy of BCC. Intended to be curative or at least locally controlling, the treatment can either be surgical or nonsurgical depending on several tumour- or patient-related factors. Especially tumour size, location, histological subtype, patient's health and wishes, possible complications, and aesthetic results should be taken into account. As there is still no preoperative method for the detection of subclinical spread, surgical therapy with 3D histology is the gold standard even in BCCs of the head and neck area. In order to ascertain the complete and hereby curative excision, several equally effective techniques are at disposal. With Mohs micrographic surgery, the histological confirmed BCC is removed in a bowl-like fashion, immediately frozen, and examined for residual tumour cells in the lateral and basal margins as long as the BCC is totally excised. 5-year recurrence rates for Mohs surgery are reported as 1\%-3\% for primary BCC and $3 \%-7 \%$ for recurrent tumours $[58,59]$. Similar results are achieved with other less known histological methods such as the La Galette technique [60]. Conventional surgery with tumour-adapted margins of safety uses a bread loaf horizontal cutting to control for complete excision. Depending on the safety margin, a higher rate of residual tumour cells and thus increased recurrence rate of $4 \%-34 \%$ is reported [58]. Curettage, electrodesiccation, and cryosurgery are further surgical approaches that are easily applied in low-risk lesions with nonaggressive histological features such as superficial BCC of the trunk. The disadvantage is, however, that the complete removal of the BCC cannot be histological proven and delayed wound healing due to thermal destruction or impairment of the basal layer may lead to unsatisfactory results. Certainly, none of these three techniques is appropriate for recurrent or morpheaform BCCs, although in general cure rates of up to $95 \%$ and higher are stated [16]. Non-surgical treatment options include radiotherapy, photodynamic therapy, and topical application of imiquimod and 5-fluorouracil. All of the proposed procedures comprise, however, the disadvantage that no treatment success can be histologically validated and thus higher recurrence rates have to be taken into account. Nonetheless, elderly patients with multiple comorbidities and inoperable tumours profit. The indication for radiotherapy-given the multitude of therapeutic options - is more limited and rather confined to postoperative recurrences or if a complete resection appears unlikely. Since there is a high risk of secondary tumors developing on the radiation side, patients with BCNS, XP, epidermodysplasia verruciformis, and iatrogenic immunosuppression should be excluded from radiotherapy. It is 
TABLE 1: Current and future $\mathrm{HH}$ pathway inhibitors.

\begin{tabular}{|c|c|c|}
\hline SMO-Inhibitors & Ongoing trials & Indication \\
\hline $\begin{array}{l}\text { GDC-0449 } \\
\text { (Erivance, Genentech) }\end{array}$ & Phase II & $\begin{array}{l}\text { BCC, medulloblastoma, ovarian cancer, small-cell lung cancer, coloractal } \\
\text { cancer (combined with cisplatin and etoposide), colorectal cancer (in } \\
\text { combination with standard chemotherapy and bevacicumab), and upper } \\
\text { gastrointestinal cancers (in combination with FOLFOLX chemotherapy) }\end{array}$ \\
\hline $\begin{array}{l}\text { BMS-833923 } \\
\text { (Bristol-Myers Squibb and } \\
\text { Exelixis) }\end{array}$ & Phase I & $\begin{array}{l}\text { BCC, BCNS, small lung cancer (versus cisplatin and etoposide), inoperable, } \\
\text { metastatic gastro, gastroesophageal or esophageal Adenocarcinoma } \\
\text { (combined with cisplatin and carpecitabine), and multiple myeloma }\end{array}$ \\
\hline $\begin{array}{l}\text { IPI-926 } \\
\text { Infinity Pharmaceuticals }\end{array}$ & Phase I & $\begin{array}{l}\text { Advanced and/or metastatic solid tumour malignancies and metastatic } \\
\text { pancreatic cancer (combined with gemcitabine) }\end{array}$ \\
\hline $\begin{array}{l}\text { LDE-225 } \\
\text { (Novartis) }\end{array}$ & Phase I/II & $\begin{array}{l}\text { Sporadic superficial and nodular skin BCC, BCNS, medulloblastoma; } \\
\text { rhabdomyosarcoma neuroblastoma, hepatoblastoma, astrocytoma, } \\
\text { advanced solid tumor cancers, and Medulloblastoma }\end{array}$ \\
\hline $\begin{array}{l}\text { PF-04449913 } \\
\text { (Pfizer) }\end{array}$ & Phase I & $\begin{array}{l}\text { select hematologic malignancies or with dasatinib in chronic myeloid } \\
\text { leukemia (CML) }\end{array}$ \\
\hline
\end{tabular}

also not recommended for patients younger than 60 years, given its potential for carcinogenesis $[61,62]$. Photodynamic therapy requires the application of a photosensitizing agent such as 5-aminolevulinic acid or its ester 3-4 hours before the protoporphyrin IX-enriched tumour cells are destroyed. Superior with regards to cosmetic outcome when compared to many other treatment options, PDT of superficial BCC showed a 1-year recurrence rate of 9.3\% [63] and is not recommended for the nodal subtype due to 5-year relapse rates of $76 \%$ [64]. Although its precise mechanism is still unknown, the once-daily application of Imiquimod 5 days per week for 6 weeks resulted in a histological clearance rate of up to $89.6 \%$ in superficial BCC [65-67]. A clear trend towards improved rates with increased frequencies of application is limited by intensified local and systemic reactions. Residual tumours after therapy are nonetheless often difficult to assess, and subtypes other than superficial BCC are no general indication for Imiquimod since multiple recurrent lesions can occur [8]. 5-fluorouracil, a topical cytostatic agent, is considered as a therapeutic alternative in patients with multiple, superficial multicentric BCCs, for example, in BCNS [68]. As a consequence of painful inflammatory and erosive reactions, the patient's compliance is often limited for this treatment option.

Given that metastasis and invasion of vital structures by BCC are extremely rare, no therapeutic "gold standard" exists. Apart from surgical procedures and an additional radiotherapy, an assortment of different chemotherapies such as doxorubicin, paclitaxel, and/or carboplatin with differing response rates have been applied up to now in order to control the tumour load and extend the patient's life expectancy $[8,69]$. Given the rare nature of metastasis, larger clinical studies have been lacking until recently.

The more detailed understanding, achieved as of late, of the molecular pathogenesis of BCC and its causative aberrant pathway has rendered a new therapeutic targeted approach possible. SMO inhibitor Cyclopamine, the teratogenic steroidal plant alkaloid, which was topically applied, succeeded already to induce regression of four sporadic BCCs [70], since then, a series of small-molecule $\mathrm{HH}$ inhibitors have been developed and are currently in clinical development. Furthest along is GDC-0449, a more specific and potent SMO inhibitor than Cyclopamine. Administered in different doses of 150, 270, and $540 \mathrm{mg}$ per day as part of a phase I study in metastatic or locally advanced BCC, an objective response in 18 of 33 patients was achieved [71]. Side effects such as hyponatraemia, fatigue, weight loss, and dyspnoea were mild to moderate. Several ongoing phase II trials investigate its efficacy in advanced BCC, medulloblastoma, and breast cancer but also in addition to other chemotherapeutic agents in pancreatic, lung, colorectal, and gastrointestinal cancer. Four other new $\mathrm{HH}$ inhibitors including LDE-225, BMS-833823, IPI-926, and PF-04449913 are currently under investigation in phase I trials. All of the tested components target so far SMO as the key regulator of the $\mathrm{HH}$ pathway. An equally effective inhibition could succeed, however, in targeting the $\mathrm{HH}$ downstream signalling. Two tested candidates GANT58 and GANT61, inhibitors of the GLI transcription, possibly provide a therapeutic alternative in case of a resistance to SMO inhibitors [72]. Also interfering with $\mathrm{HH}$ target gene transcription and therefore of potential therapeutic interest in BCC is the new field of microRNAs. While one single microRNA regulates hundreds of target genes, the task is to focus its efficacy on the essential target and thus minimize its side effects, which still needs to be mastered (Table 1) [73].

As discussed by Epstein, the use of tyrosine kinase inhibitors, sorafenib or imatinib, seems sensible because $\operatorname{PDGFR} \alpha$ is supposed to mediate downstream effects in $\mathrm{HH}$ signalling [14]. The assortment of further new potential agents for prevention as well as treatment in BCC is plentiful, ranging from Vitamin A and D derivates, NSAID, and DNA repair enzymes up to Melanocortin peptides therapeutics. Certainly due to the lack of knowledge of their precise functioning and how, or if at all, they interact with $\mathrm{HH}$ pathway, results are so far promising but inconclusive. It may therefore not be surprising that even the widely recognized and in its molecular effects initially well understood standard therapy with systemic retinoids fails to prevent the recurrence of sporadic BCC [74]. 


\section{Conclusion}

In view of those remarkable oncogenomic achievements in the understanding of BCC carcinogenesis, a curative breakthrough, especially in hereditary, locally advanced or metastatic cases, seems imminent. First promising data are yet too scarce to obtain detailed pieces of information about dosage, side effects, response, recurrence, and survival rates or possible medical interactions. Not sufficiently known but crucial is certainly the impact of the type of $\mathrm{HH}$ mutations and their combinations for the various clinical subtypes of BCC. The change from a phenotype-correlated diagnosis to a genotype analysis, at least in advanced tumours, is obvious. But is BCC in all its clinical and histological variations to be reclassified according to its genotype? Genetic analysis will undoubtedly change the classification and subsequently treatment algorithms for BCC. The open intruiging question remains if there is a link between $\mathrm{HH}$ mutation, histology, and its clinical aspects that would simplify the indication for a targeted therapy. Of equal importance in this complex interplay are without doubt epigenetic phenomena and environmental factors that are at best only initially recognized so far. Definitely many more future studies are needed to answer the large number of interesting questions that the discovery of aberrant $\mathrm{HH}$ pathway for BCC raised.

\section{References}

[1] W. Binns, L. F. James, J. L. Shupe, and G. Everett, "A congenital cyclopian-type malformation in lambs induced by maternal ingestion of a range plant, Veratrum californicum," American Journal of Veterinary Research, vol. 24, pp. 1164-1175, 1963.

[2] R. J. Keeler and W. Binns, "Teratogenic compounds of Veratrum californicum (Durand). 3. Malformations of the veratramine-induced type from ingestion of plant or roots," Proceedings of the Society for Experimental Biology and Medicine, vol. 126, no. 2, pp. 452-454, 1967.

[3] M. K. Cooper, J. A. Porter, K. E. Young, and P. A. Beachy, "Teratogen-mediated inhibition of target tissue response to Shh signaling," Science, vol. 280, no. 5369, pp. 1603-1607, 1998.

[4] H. Hahn, C. Wicking, P. G. Zaphiropoulos et al., "Mutations of the human homolog of Drosophila patched in the nevoid basal cell carcinoma syndrome," Cell, vol. 85, no. 6, pp. 841851, 1996.

[5] H. Grimmer, "Histological picture report no.20l. Basalioma of the vulva (basal cell carcinoma Krompecher 1900)," Zeitschrift fur Haut und Geschlechtskrankheiten, vol. 43, no. 5, pp. 25-40, 1967.

[6] K. K. Youssef, A. Van Keymeulen, G. Lapouge et al., "Identification of the cell lineage at the origin of basal cell carcinoma," Nature Cell Biology, vol. 12, no. 3, pp. 299-305, 2010.

[7] Z. Holíková, D. Massi, T. Lotti, and J. Hercogová, "Insight into the pathogenesis of sporadic basal cell carcinoma," International Journal of Dermatology, vol. 43, no. 12, pp. 865869, 2004.

[8] T. K. Eigentler, A. Kamin, B. M. Weide et al., "A phase III, randomized, open label study to evaluate the safety and efficacy of imiquimod 5\% cream applied thrice weekly for 8 and 12 weeks in the treatment of low-risk nodular basal cell carcinoma," Journal of the American Academy of Dermatology, vol. 57, no. 4, pp. 616-621, 2007.

[9] E. De Vries, M. Louwman, M. Bastiaens, F. De Gruijl, and J. W. Coebergh, "Rapid and continuous increases in incidence rates of basal cell carcinoma in the Southeast Netherlands since 1973," Journal of Investigative Dermatology, vol. 123, no. 4, pp. 634-638, 2004.

[10] T. L. Diepgen and V. Mahler, "The epidemiology of skin cancer," British Journal of Dermatology, vol. 146, supplement 61, pp. 1-6, 2002.

[11] G. B. E. Jemec and E. A. Holm, "Nonmelanoma skin cancer in organ transplant patients," Transplantation, vol. 75, no. 3, pp. 253-257, 2003.

[12] C. S. M. Wong, R. C. Strange, and J. T. Lear, "Basal cell carcinoma," British Medical Journal, vol. 327, no. 7418, pp. 794-798, 2003.

[13] J. T. Lear, B. B. Tan, A. G. Smith et al., "Risk factors for basal cell carcinoma in the UK: case-control study in 806 patients," Journal of the Royal Society of Medicine, vol. 90, no. 7, pp. 371374, 1997.

[14] E. H. Epstein, "Basal cell carcinomas: attack of the hedgehog," Nature Reviews Cancer, vol. 8, no. 10, pp. 743-754, 2008.

[15] B. K. Armstrong and A. Kricker, "The epidemiology of UV induced skin cancer," Journal of Photochemistry and Photobiology B, vol. 63, no. 1-3, pp. 8-18, 2001.

[16] A. I. Rubin, E. H. Chen, and D. Ratner, "Basal-cell carcinoma," New England Journal of Medicine, vol. 353, no. 21, pp. 22622269, 2005.

[17] L. J. Christenson, T. A. Borrowman, C. M. Vachon et al., "Incidence of basal cell and squamous cell carcinomas in a population younger than 40 years," Journal of the American Medical Association, vol. 294, no. 6, pp. 681-690, 2005.

[18] R. Cui, H. R. Widlund, E. Feige et al., "Central role of p53 in the suntan response and pathologic hyperpigmentation," Cell, vol. 128, no. 5, pp. 853-864, 2007.

[19] H. W. Walling, S. W. Fosko, P. A. Geraminejad, D. C. Whitaker, and C. J. Arpey, "Aggressive basal cell carcinoma: presentation, pathogenesis, and management," Cancer and Metastasis Reviews, vol. 23, no. 3-4, pp. 389-402, 2004.

[20] S. N. Snow, W. Sahl, J. S. Lo et al., "Metastatic basal cell carcinoma: report of five cases," Cancer, vol. 73, no. 2, pp. 328335, 1994.

[21] R. J. Gorlin, “Nevoid basal cell carcinoma syndrome," Dermatologic Clinics, vol. 13, no. 1, pp. 113-125, 1995.

[22] R. L. Johnson, A. L. Rothman, J. Xie et al., "Human homolog of patched, a candidate gene for the basal cell nevus syndrome," Science, vol. 272, no. 5268, pp. 1668-1671, 1996.

[23] O. Lupi, "Correlations between the Sonic Hedgehog Pathway and basal cell carcinoma," International Journal of Dermatology, vol. 46, no. 11, pp. 1113-1117, 2007.

[24] P. W. Ingham and A. P. McMahon, "Hedgehog signaling in animal development: paradigms and principles," Genes and Development, vol. 15, no. 23, pp. 3059-3087, 2001.

[25] B. Z. Stanton and L. F. Peng, "Small-molecule modulators of the Sonic Hedgehog signaling pathway," Molecular BioSystems, vol. 6, no. 1, pp. 44-54, 2010.

[26] S. J. Scales and F. J. de Sauvage, "Mechanisms of Hedgehog pathway activation in cancer and implications for therapy," Trends in Pharmacological Sciences, vol. 30, no. 6, pp. 303-312, 2009. 
[27] M. E. Hutchin, M. S. T. Kariapper, M. Grachtchouk et al., "Sustained Hedgehog signaling is required for basal cell carcinoma proliferation and survival: conditional skin tumorigenesis recapitulates the hair growth cycle," Genes and Development, vol. 19, no. 2, pp. 214-223, 2005.

[28] J. Taipale and P. A. Beachy, "The Hedgehog and Wnt signalling pathways in cancer," Nature, vol. 411, no. 6835, pp. 349-354, 2001.

[29] J. Reifenberger, M. Wolter, C. B. Knobbe et al., "Somatic mutations in the PTCH, SMOH, SUFUH and TP53 genes in sporadic basal cell carcinomas," British Journal of Dermatology, vol. 152, no. 1, pp. 43-51, 2005.

[30] E. Lindström, T. Shimokawa, R. Toftgård, and P. G. Zaphiropoulos, "PTCH mutations: distribution and analyses," Human Mutation, vol. 27, no. 3, pp. 215-219, 2006.

[31] A. Ziegler, D. J. Leffell, S. Kunala et al., "Mutation hotspots due to sunlight in the p53 gene of nonmelanoma skin cancers," Proceedings of the National Academy of Sciences of the United States of America, vol. 90, no. 9, pp. 4216-4220, 1993.

[32] M.-Y. Kim, H. J. Park, S.-C. Baek, D. G. Byun, and D. Houh, "Mutations of the p53 and PTCH gene in basal cell carcinomas: UV mutation signature and strand bias," Journal of Dermatological Science, vol. 29, no. 1, pp. 1-9, 2002.

[33] R. Pola, L. E. Ling, M. Silver et al., "The morphogen Sonic hedgehog is an indirect angiogenic agent upregulating two families of angiogenic growth factors," Nature Medicine, vol. 7, no. 6, pp. 706-711, 2001.

[34] J. Xie, M. Murone, S.-M. Luoh et al., "Activating Smoothened mutations in sporadic basal-cell carcinoma," Nature, vol. 391, no. 6662, pp. 90-92, 1998.

[35] E. Kump, J. Ji, M. Wernli, P. Häusermann, and P. Erb, "Gli2 upregulates cFlip and renders basal cell carcinoma cells resistant to death ligand-mediated apoptosis," Oncogene, vol. 27, no. 27, pp. 3856-3864, 2008.

[36] M. Athar, C. Li, X. Tang et al., "Inhibition of smoothened signaling prevents ultraviolet B-induced basal cell carcinomas through regulation of fas expression and apoptosis," Cancer Research, vol. 64, no. 20, pp. 7545-7552, 2004.

[37] R. L. H. Bigelow, N. S. Chari, A. B. Undén et al., "Transcriptional regulation of bcl-2 mediated by the sonic hedgehog signaling pathway through gli-1," Journal of Biological Chemistry, vol. 279, no. 2, pp. 1197-1205, 2004.

[38] J. Xie, M. Aszterbaum, X. Zhang et al., "A role of PDGFR $\alpha$ in basal cell carcinoma proliferation," Proceedings of the National Academy of Sciences of the United States of America, vol. 98, no. 16, pp. 9255-9259, 2001.

[39] T. Eichberger, G. Regl, M. S. Ikram et al., "FOXE1, a new transcriptional target of GLI2, is expressed in human epidermis and basal cell carcinoma," Journal of Investigative Dermatology, vol. 122, no. 5, pp. 1180-1187, 2004.

[40] M.-T. Teh, S.-T. Wong, G. W. Neill, L. R. Ghali, M. P. Philpott, and A. G. Quinn, "FOXM1 is a downstream target of Gli1 in basal cell carcinomas," Cancer Research, vol. 62, no. 16, pp. 4773-4780, 2002.

[41] D. A. Haber and J. Settleman, "Cancer: drivers and passengers," Nature, vol. 446, no. 7132, pp. 145-146, 2007.

[42] R. J. Levitt, Y. Zhao, M.-J. Blouin, and M. Pollak, "The hedgehog pathway inhibitor cyclopamine increases levels of p27, and decreases both expression of IGF-II and activation of Akt in PC-3 prostate cancer cells," Cancer Letters, vol. 255, no. 2, pp. 300-306, 2007.
[43] S. Yang, T. Andl, V. Grachtchouk et al., "Pathological responses to oncogenic Hedgehog signaling in skin are dependent on canonical Wnt/ $\beta$-catenin signaling," Nature Genetics, vol. 40, no. 9, pp. 1130-1135, 2008.

[44] S. Couvé-Privat, B. Bouadjar, M. F. Avril, A. Sarasin, and L. Daya-Grosjean, "Significantly high levels of ultravioletspecific mutations in the smoothened gene in basal cell carcinomas from dna repair-deficient xeroderma pigmentosum patients," Cancer Research, vol. 62, no. 24, pp. 7186-7189, 2002.

[45] S.-I. Moriwaki, S. Ray, R. E. Tarone, K. H. Kraemer, and L. Grossman, "The effect of donor age on the processing of UVdamaged DNA by cultured human cells: reduced DNA repair capacity and increased DNA mutability," Mutation Research, vol. 364, no. 2, pp. 117-123, 1996.

[46] L. Daya-Grosjean and A. Sarasin, "UV-specific mutations of the human patched gene in basal cell carcinomas from normal individuals and xeroderma pigmentosum patients," Mutation Research, vol. 450, no. 1-2, pp. 193-199, 2000.

[47] N. Pandeya, D. M. Purdie, A. Green, and G. Williams, "Repeated occurrence of basal cell carcinoma of the skin and multifailure survival analysis: follow-up data from the Nambour Skin Cancer Prevention Trial," American Journal of Epidemiology, vol. 161, no. 8, pp. 748-754, 2005.

[48] S. Y. Kang, K. G. Lee, W. Lee et al., "Polymorphisms in the DNA repair gene XRCC1 associated with basal cell carcinoma and squamous cell carcinoma of the skin in a Korean population," Cancer Science, vol. 98, no. 5, pp. 716720, 2007.

[49] S. Han, H.-T. Zhang, Z. Wang et al., "DNA repair gene XRCC3 polymorphisms and cancer risk: a meta-analysis of 48 casecontrol studies," European Journal of Human Genetics, vol. 14, no. 10, pp. 1136-1144, 2006.

[50] J. Han, S. E. Hankinson, G. A. Colditz, and D. J. Hunter, "Genetic variation in XRCC1, sun exposure, and risk of skin cancer," British Journal of Cancer, vol. 91, no. 8, pp. 1604-1609, 2004.

[51] N. R. Jacobsen, B. A. Nexø, A. Olsen et al., "No association between the DNA repair gene XRCC3 T241M polymorphism and risk of skin cancer and breast cancer," Cancer Epidemiology Biomarkers and Prevention, vol. 12, no. 6, pp. 584-585, 2003.

[52] F. Festa, R. Kumar, S. Sanyal et al., "Basal cell carcinoma and variants in genes coding for immune response, DNA repair, folate and iron metabolism," Mutation Research, vol. 574, no. 1-2, pp. 105-111, 2005.

[53] J. Han, G. A. Colditz, L. D. Samson, and D. J. Hunter, "Polymorphisms in DNA double-strand break repair genes and skin cancer risk," Cancer Research, vol. 64, no. 9, pp. 30093013, 2004.

[54] J. Han, P. Kraft, G. A. Colditz, J. Wong, and D. J. Hunter, "Melanocortin 1 receptor variants and skin cancer risk," International Journal of Cancer, vol. 119, no. 8, pp. 1976-1984, 2006.

[55] M. T. Bastiaens, J. A. C. Ter Huurne, C. Kielich et al., "Melanocortin-1 receptor gene variants determine the risk of nonmelanoma skin cancer independently of fair skin and red hair," American Journal of Human Genetics, vol. 68, no. 4, pp. 884-894, 2001.

[56] M. Wintzen, M. Yaar, J. P. H. Burbach, and B. A. Gilchrest, "Proopiomelanocortin gene product regulation in keratinocytes," Journal of Investigative Dermatology, vol. 106, no. 4, pp. 673-678, 1996. 
[57] A. Slominski, R. Paus, and J. Wortsman, "Can some melanotropins modulate keratinocyte proliferation?” Journal of Investigative Dermatology, vol. 97, no. 4, p. 747, 1991.

[58] K. Mosterd, G. A. Krekels, F. H. Nieman et al., "Surgical excision versus Mohs' micrographic surgery for primary and recurrent basal-cell carcinoma of the face: a prospective randomised controlled trial with 5-years' follow-up," The Lancet Oncology, vol. 9, no. 12, pp. 1149-1156, 2008.

[59] I. Leibovitch, S. C. Huilgol, D. Selva, S. Richards, and R. Paver, "Basal cell carcinoma treated with Mohs surgery in Australia II. Outcome at 5-year follow-up," Journal of the American Academy of Dermatology, vol. 53, no. 3, pp. 452-457, 2005.

[60] T. Wetzig, J. Maschke, M. Kendler, and J. C. Simon, "Treatment of basal cell carcinoma," Journal der Deutschen Dermatologischen Gesellschaft, vol. 7, no. 12, pp. 1075-1084, 2009.

[61] N. R. Telfer, G. B. Colver, and C. A. Morton, "Guidelines for the management of basal cell carcinoma," British Journal of Dermatology, vol. 159, no. 1, pp. 35-48, 2008.

[62] M. Veness and S. Richards, "Role of modern radiotherapy in treating skin cancer," Australasian Journal of Dermatology, vol. 44, no. 3, pp. 159-166, 2003.

[63] R. M. Szeimies, S. Ibbotson, D. F. Murrell et al., "A clinical study comparing methyl aminolevulinate photodynamic therapy and surgery in small superficial basal cell carcinoma (8$20 \mathrm{~mm}$ ), with a 12-month follow-up," Journal of the European Academy of Dermatology and Venereology, vol. 22, no. 11, pp. 1302-1311, 2008.

[64] L. E. Rhodes, M. A. De Rie, R. Leifsdottir et al., "Five-year follow-up of a randomized, prospective trial of topical methyl aminolevulinate photodynamic therapy vs surgery for nodular basal cell carcinoma," Archives of Dermatology, vol. 143, no. 9, pp. 1131-1136, 2007.

[65] H. Gollnick, C. G. Barona, R. G. J. Frank et al., "Recurrence rate of superficial basal cell carcinoma following treatment with imiquimod $5 \%$ cream: conclusion of a 5 -year long-term follow-up study in Europe," European Journal of Dermatology, vol. 18, no. 6, pp. 677-682, 2008.

[66] J. Geisse, I. Caro, J. Lindholm, L. Golitz, P. Stampone, and M. Owens, "Imiquimod 5\% cream for the treatment of superficial basal cell carcinoma: results from two phase III, randomized, vehicle-controlled studies," Journal of the American Academy of Dermatology, vol. 50, no. 5, pp. 722-733, 2004.

[67] M. A. Stanley, "Imiquimod and the imidazoquinolones: mechanism of action and therapeutic potential," Clinical and Experimental Dermatology, vol. 27, no. 7, pp. 571-577, 2002.

[68] K. Gross, L. Kircik, and G. Kricorian, "5\% 5-fluorouracil cream for the treatment of small superficial basal cell carcinoma: efficacy, tolerability, cosmetic outcome, and patient satisfaction," Dermatologic Surgery, vol. 33, no. 4, pp. 433-439, 2007.

[69] B. Carneiro, W. Watkin, U. Mehta, and B. Brockstein, "Metastatic basal cell carcinoma: complete response to chemotherapy and associated pure red cell aplasia," Cancer Investigation, vol. 24, no. 4, pp. 396-400, 2006.

[70] S. Tabs and O. Avci, "Induction of the differentiation and apoptosis of tumor cells in vivo with efficiency and selectivity," European Journal of Dermatology, vol. 14, no. 2, pp. 96-102, 2004.

[71] D. D. Von Hoff, P. M. LoRusso, C. M. Rudin et al., "Inhibition of the hedgehog pathway in advanced basal-cell carcinoma," New England Journal of Medicine, vol. 361, no. 12, pp. 1164 $1172,2009$.
[72] G. J. Weiss and D. D. Von Hoff, "Hunting the hedgehog pathway," Clinical Pharmacology and Therapeutics, vol. 87, no. 6, pp. 743-747, 2010.

[73] K. M. Nelson and G. J. Weiss, "MicroRNAs and cancer: past, present, and potential future," Molecular Cancer Therapeutics, vol. 7, no. 12, pp. 3655-3660, 2008.

[74] N. Levine, T. E. Moon, B. Cartmel et al., "Trial of retinol and isotretinoin in skin cancer prevention: a randomized, double-blind, controlled trial. Southwest Skin Cancer Prevention Study Group," Cancer Epidemiology Biomarkers and Prevention, vol. 6, no. 11, pp. 957-961, 1997. 


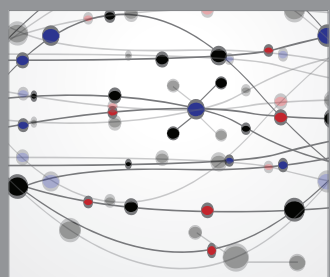

The Scientific World Journal
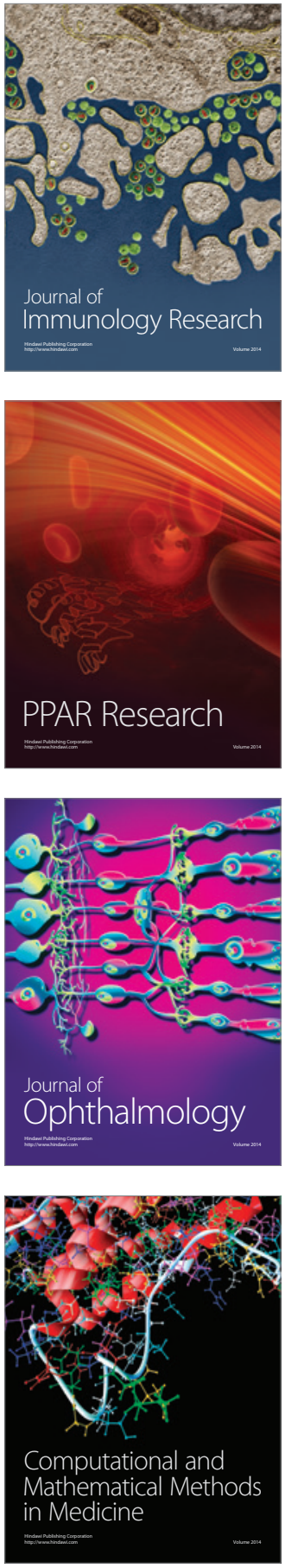

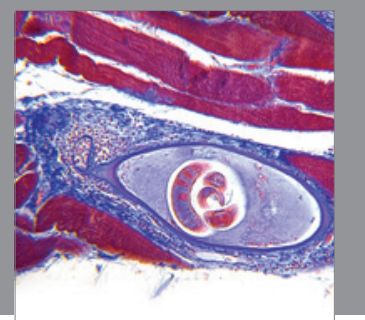

Gastroenterology

Research and Practice
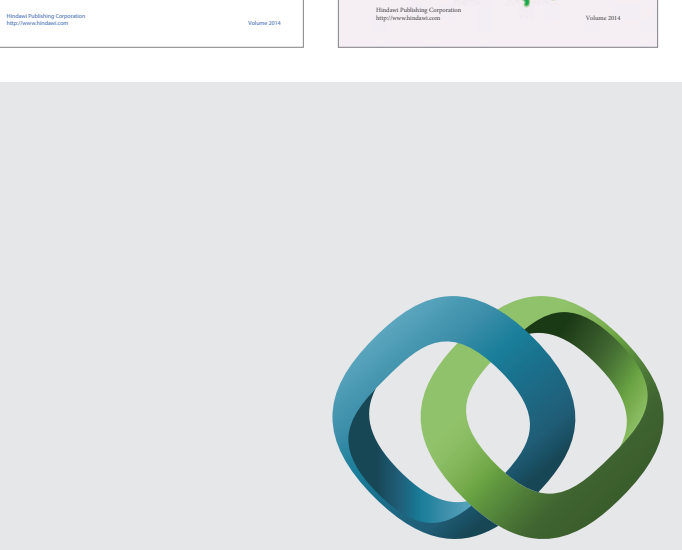

\section{Hindawi}

Submit your manuscripts at

http://www.hindawi.com
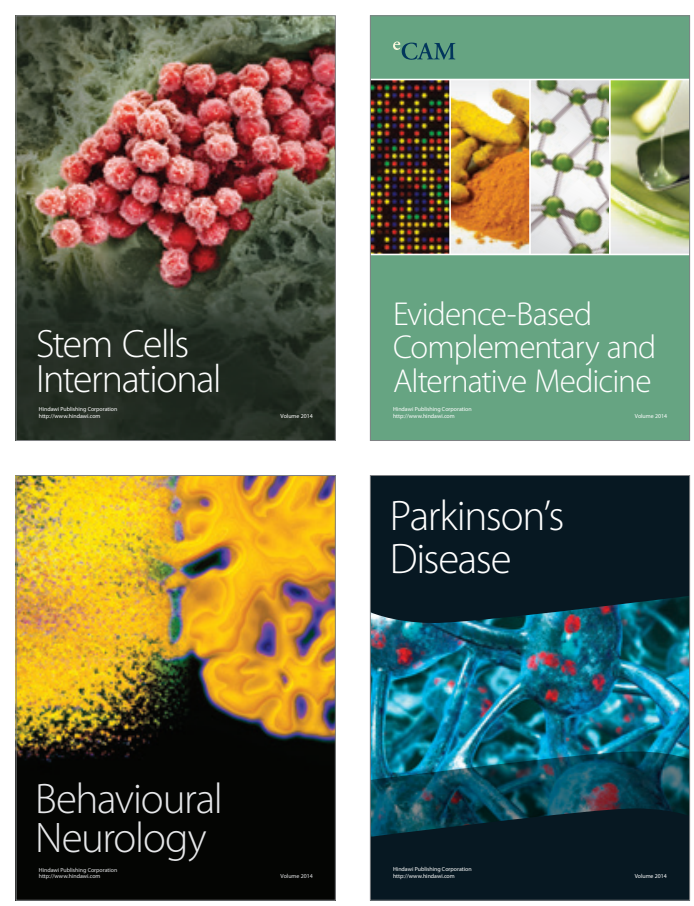

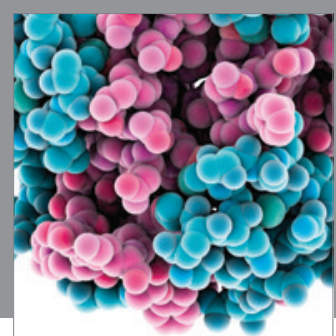

Journal of
Diabetes Research

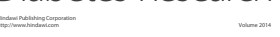

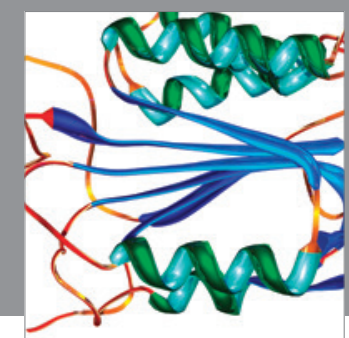

Disease Markers
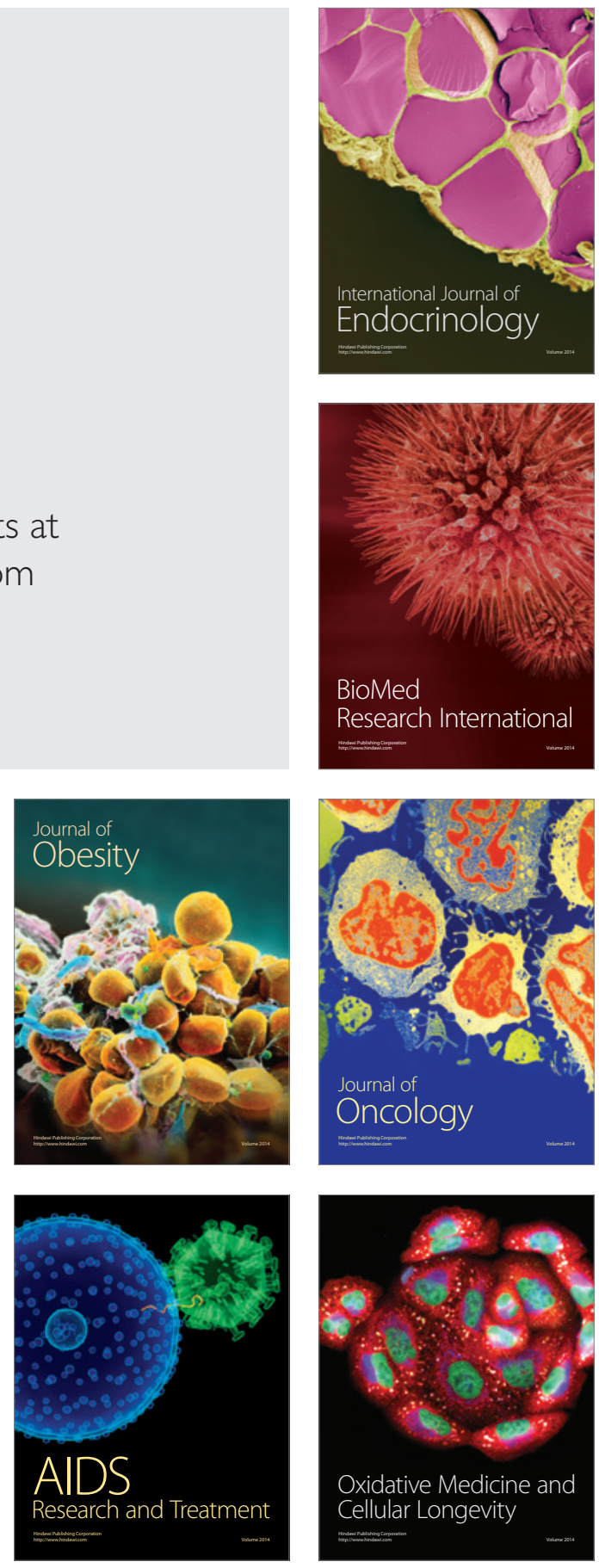